\title{
Effect of Genital Warts on Female Sexual Function and Quality of Life: An Egyptian Study
}

\section{Original Article}

\author{
Fatma M. El-Esawy and Heba M. Ahmed \\ Department of Dermatology and Andrology, Faculty of Medicine, Benha University, Benha, \\ Egypt
}

\begin{abstract}
Background: Female patients with anogenital warts often suffer from anxiety of the effect of the disease on their sexual and social relationships that negatively affect the quality of life of woman.

Objective: To evaluate the female sexual dysfunction (FSD) and QOL among married women suffering from genital warts (GWs).

Patients and Methods: Fifty married women suffering from GWs with established marital relationships were enrolled in this study. A questionnaire formula distinguished by authors was applied for the contributors.

Results: About $98 \%$ of the participants had sexual problems with total FSFI score17.2 \pm 6.2 . FSD correlated with declined quality of life.

Conclusion: Genital warts have negative wide-ranging effects on patients' quality of life and sexual functions.
\end{abstract}

Key Words: FSD, genital wart, QOL.

Received: 9 January 2017, Accepted: 15 March 2017

Corresponding Author: Fatma M Elesawy, Tel.: 01006034708, E-mail: Fatmaelesawy99@yahoo.com

ISSN: 2090-6048, June 2017, Vol. 7, No. 2

\section{INTRODUCTION}

Patients with genital warts (GWs), worried about the indefinite timeline and perspectives of recovery, they were often depressed and had low self-esteem. The patients' self-image as well as their social lives were affected by the stigmatization caused by the disease. Patients found it difficult to detach themselves from their GWs because of the repeated treatments and the negative effects on their sex lives ${ }^{[1,2]}$. Female sexual dysfunction (FSD) is defined as disorders of sexual desire, arousal, orgasm, and sexual pain, which lead to personal distress ${ }^{[3]}$. The patients suffering from GWs described themselves as 'impure, repulsive and sexually unattractive' and seriously questioned how others might find them attractive when they did not even like themselves. Problems often arose in existing relationships because of worries about the source of the infection or a lack of sexual desire4.Their libido is low, their sexual initiative is reduced, and pleasure is often lost during intercourse because of awareness of the warts and fear of transmitting the disease ${ }^{[5]}$.

Sexual function of female patients with GW had been studied worldwide. However, no adequate studies in Arab countries around it, so this study was designed to study sexual performs and quality of life among our Egyptian patients.

\section{PATIENTS AND METHODS}

This cross-sectional study was conducted on 50 married women with GWs referred to the Outpatient Clinics of Dermatology\& Andrology Department and Gynecology \& Obstetrics Department in Benha University Hospital in the period between April 2016 and October 2016. The study 
questionnaire was approved by the Ethics Committee of Benha Human Research.

\section{Inclusion criteria}

Married women aged between 18- 45 years and suffering from GWs for at least three months. Selected women were sexually active for the past 6 months. In order to answer the questionnaire also to sign the consent, each of the participants was literate.

\section{Exclusion criteria}

Existence of medical disorders affecting female sexuality "e.g. neuropsychiatric diseases, diabetes during the past three months" led to exclusion. Women exceeded the age of 45 years were also excluded.

\section{Study instrument}

The questionnaire consisted of three parts. The first part included the demographic variables; i.e. age, residence, education, employment, duration of marriage, husband's age, education level, occupation, disease characters and treatment data. The second part was directed to assess sexual function by female sexual function index (FSFI) and the third one was used to assess quality of life by Dermatology Life Quality Index (DLQI).

Female Sexual Function Index (FSFI) was designed by Rosen et al. ${ }^{[6]}$, this questionnaire consists of 19 questions investigating the subjects in 6 domains of sexual desire, arousal, lubrication, orgasm, satisfaction, and pain during intercourse. It was translated into several languages and applied universally because of its suitable phrasing and clearscale structure. The Arabic version of FSFI questionnaire (Ar-FSFI) was used in this study ${ }^{[7]}$. In this questionnaire, the questions are scored based on 0- 5 scoring system and the score of each domain is calculated through summing up the scores of that domain's questions and multiplying the obtained number by the domain factor (namely 0.6 for desire, 0.3 for lubrication and arousal, and 0.4 for orgasm, satisfaction and pain). The scores less than 4.28, 5.08, 5.45, $5.05,5.04$, and 5.51 in the desire domain, arousal domain, lubrication domain, orgasm domain, satisfaction domain, and pain domain, respectively, were used to classify the participants as having problems in that domain. The sexual function total score is obtained from the sum of the scores of all the domains and is ranged from 2- 36. The cut-off score used to demarcate sexual dysfunction on the total FSFI score was achieved from a validation study below 26.55 to symbolize sexual dysfunction 6,8 .

The dermatology life quality index (DLQI) consists of 10 patient-rated items with a maximum score of ${ }^{[30]}$. The 10 items covers six domains (symptoms, feelings, routine daily activities, sports activities, work and school, personal relationships, and treatment) during the preceding one week. Overall score is calculated by summing the results from each question, which yield a result between 0 and 30 , with higher scores representing a greater impact on quality of life $\mathrm{e}^{[9,10]}$.

\section{Procedures}

The investigator recruited the women with GWs after explaining the content and underlying principle of the study. For privacy and confidentiality, individual face to face interview was held in a closed room.. The questionnaire was explained to the subjects, who were taught on how to fill it, with the surveyor was reachable for any clarification.

\section{Statistical analysis}

Collected data were tabulated and analyzed using Statistical Package for Social Science (SPSS) version 16 software Inc, and Chicago, Ill, USA. Categorical data were presented as number and percentages while quantitative data were expressed as mean \pm standard deviation and range. Goodness of fit test and " $Z$ " test used to analyze categorical variables. Quantitative data were tested for normality using Kolmogorov Smirnove test, using St. " $t$ " test, ANOVA test and Person's correlation coefficient ( $r$ ) as found normally distributed, $(P<0.05$ was considered significant).

\section{RESULTS}

Regarding the socio-demographic features of the participants, the age range was $20-45$ years old with the mean of $32.5 \pm 7.9$ years. Of them, $20 \%$ had jobs, and $48 \%$ were living in urban area. Regarding the duration of marriage, $46 \%$ were married for more than five years. Besides, 14\% were university-graduates. As regard husbands' demographic characters, $50.54 \%$ exceeded the age of 30 years, $38 \%$ had elementary education, and $44.7 \%$ were employed.

The clinical data about GWs, $74 \%$ had multiple warts with mean of duration of $6.12 \pm 2.4$ monthes, $12 \%$ had some knowledge about Human Papillomavirus (HPV), 42\% had recurrent GWs, 86\% were treated with cryotherapy, $68 \%$ felt pain, embarrassment and worried about treatment effectiveness and duration, $20 \%$ of the patients had sexual problems before GWs, $42 \%$ were very worried about HPV, 38\% were very worried about the cancer.

In this study, $34 \%$ of the participants were confident that her partner will accept her, $18 \%$ were worried about intercourse in the future and doubt of wart transmission to their partners, and $48 \%$ were worried about having more genital warts after intercourse. As regard husband infection with GWs, $78 \%$ had GWs. Noteworthy, $8 \%$ of husbands were using condom. 
About $98 \%$ of the participants having sexual dysfunction, total FSFI score range (3.6 -27.3) with mean \pm SD (17.2 \pm 6.2$)$. The sexual function domains showed the lowest mean scores to be related to desire $(3.26 \pm 1.2)$, arousal $(2.64 \pm 1.33)$, orgasm $(1.85 \pm 1.1)$, pain $(3.09 \pm$ $1.5)$, satisfaction $(2.96 \pm 1.02)$, and lubrication (3.37 \pm 1.6$)$ (Table 1).

The Interpretation of DLQI among the studied participants $50 \%$ had very large effect on patient's life. The domains with the greatest impact on the patients' quality of life were embarrassment, problems with partner, friends or relatives, sexual difficulties and treatment problems. Difficulty doing sports was the domain that least affected the patients' quality of life in this sample (Table 2).

\section{Underlying factors of sexual problem}

In the analysis of factors associated with FSD, there were significant direct correlations $(P$-value $<0.05)$ between female having sexual dysfunction and women age $(p=0.002)$, duration of marriage $(p=0.008)$, disease duration $(p=0.001)$, HPV knowledge $(p=0.017)$, GWs (number, recurrent). There were non-significant correlations $(P$-value $>0.05)$ between female having sexual dysfunction and residence $(P=0.09)$, level of education $(P=0.85)$, working status $(P=0.94)$, husband infection with GWs $(P=0.91)$, condom use $(P=0.18)$, and type of treatment $(P=0.87)$ as shown in tables $3-5$. There was a significant correlation between the FSD score and impaired QOL $(P=0.001 \& \mathrm{r}=0.803)$.

Table 1: FSFI scores among the patients.

\begin{tabular}{|c|c|c|c|}
\hline \multirow{8}{*}{ FSFI } & Variables & Mean \pm SD & Range \\
\hline & Desire domain & $3.26 \pm 1.2$ & $1.2-5.4$ \\
\hline & Arousal domain & $2.64 \pm 1.33$ & $0.0-4.8$ \\
\hline & Lubrication domain & $3.37 \pm 1.6$ & $0.0-5.7$ \\
\hline & Orgasm domain & $1.85 \pm 1.1$ & $0.0-4.0$ \\
\hline & Satisfaction domain & $2.96 \pm 1.02$ & $1.2-5.2$ \\
\hline & Pain domain & $3.09 \pm 1.5$ & $0.0-5.2$ \\
\hline & Total score* & $17.2 \pm 6.2$ & $3.6-27.3$ \\
\hline
\end{tabular}

* Total Score $\leq 26.55$ indicates sexual dysfunction.

Table 2: Interpretation of DLQI among the studied females

\begin{tabular}{lccc}
\hline DLQI & No. & $\%$ & Goodness of fit \& P \\
\hline $\begin{array}{l}\text { Small effect on } \\
\text { patient's life (2-5) }\end{array}$ & 2 & 4.0 & $19.4 \&$ \\
$\begin{array}{l}\text { Moderate effect on } \\
\text { patient's life (6-10) }\end{array}$ & 23 & 46.0 & $<0.001$ (S) \\
$\begin{array}{l}\text { Very large effect on } \\
\text { patient's life (11-20) }\end{array}$ & 25 & 50.0 & \\
Total & & & 100.0 \\
\hline
\end{tabular}


Table 3: Correlation between FSFI, DLQI and the studied variables

\begin{tabular}{|c|c|c|c|c|}
\hline \multirow[t]{2}{*}{ With } & \multicolumn{2}{|c|}{ FSFI } & \multicolumn{2}{|c|}{ DLQI } \\
\hline & r & $\mathrm{P}$ & $\mathrm{r}$ & $\mathrm{P}$ \\
\hline Age & -0.432 & $0.002(\mathrm{~S})$ & -0.097 & 0.5 \\
\hline Duration of marriage & -0.373 & $0.008(\mathrm{~S})$ & -0.194 & 0.18 \\
\hline Disease duration & -0.663 & $<0.001$ (HS) & 0.614 & $<0.001(\mathrm{~S})$ \\
\hline
\end{tabular}

Table 4: Relation between FSFI \& QOL and some socio-demographic results.

\begin{tabular}{|c|c|c|c|c|c|c|}
\hline \multirow[t]{2}{*}{ Variable } & & \multirow[t]{2}{*}{ n. } & \multicolumn{2}{|c|}{ FSFI } & \multicolumn{2}{|c|}{ DLQI } \\
\hline & & & Mean \pm SD & St."t" \& P & Mean \pm SD & St."t" \& P \\
\hline \multirow{4}{*}{ Residence } & Urban & 24 & $15.6 \pm 7.34$ & & $12.1 \pm 3.74$ & \\
\hline & & & & $\begin{array}{c}1.73 \& 0.09 \\
(\mathrm{NS})\end{array}$ & & $\begin{array}{c}3.64 \& 0.001 \\
(\mathrm{HS})\end{array}$ \\
\hline & Rural & 26 & $18.6 \pm 4.66$ & & $9.04 \pm 2.08$ & \\
\hline & Not educated & 8 & $16.6 \pm 6.16$ & & $9.7 \pm 4.23$ & \\
\hline \multirow{4}{*}{$\begin{array}{l}\text { Patient } \\
\text { education }\end{array}$} & Read and write & 21 & $16.4 \pm 5.62$ & & $10.0 \pm 2.90$ & \\
\hline & & & & $\begin{array}{c}\text { ANOVA }=0.26 \\
\& 0.85 \text { (NS) }\end{array}$ & & $\begin{array}{c}\text { ANOVA }= \\
0.64 \& 0.59(\mathrm{NS})\end{array}$ \\
\hline & Secondary & 14 & $18.1 \pm 6.48$ & & $11.2 \pm 3.46$ & \\
\hline & University & 7 & $18.0 \pm 8.34$ & & $11.4 \pm 3.59$ & \\
\hline \multirow[t]{3}{*}{$\begin{array}{l}\text { Working } \\
\text { status }\end{array}$} & Working & 16 & $17.1 \pm 6.79$ & $\begin{array}{c}\text { St."t" }=0.06 \& \\
0.94(\mathrm{NS})\end{array}$ & $11.9 \pm 2.98$ & $\begin{array}{l}\text { St."t"=2.02 } \\
\& 0.049(\mathrm{~S})\end{array}$ \\
\hline & Not working & 34 & $17.2 \pm 6.03$ & & $9.9 \pm 3.36$ & \\
\hline & Some & 6 & $22.7 \pm 1.85$ & & $9.6 \pm 4.27$ & \\
\hline \multirow[t]{2}{*}{$\begin{array}{l}\text { HPV } \\
\text { knowledge }\end{array}$} & Little & 16 & $14.5 \pm 7.25$ & $\begin{array}{c}\mathrm{ANOVA}=4.44 \\
\& 0.017(\mathrm{~S})\end{array}$ & $11.1 \pm 3.00$ & $\begin{array}{c}\text { ANOVA= } \\
0.48 \\
\& 0.62(\mathrm{NS})\end{array}$ \\
\hline & Non & 28 & $17.5 \pm 5.40$ & & $10.3 \pm 3.40$ & \\
\hline
\end{tabular}


Table 5: Relation between FSFI \& QOL and characters of the genital warts

\begin{tabular}{|c|c|c|c|c|c|c|}
\hline \multirow{2}{*}{ Variable } & & \multirow{2}{*}{ n. } & \multicolumn{2}{|c|}{ FSFI } & \multicolumn{2}{|c|}{ DLQI } \\
\hline & & & Mean \pm SD & St."t" \& P & Mean \pm SD & St."t" \& P \\
\hline \multirow{3}{*}{ No. of GW } & Single & 13 & $22.0 \pm 2.68$ & & $8.5 \pm 2.47$ & \\
\hline & & & & $3.67 \& 0.001(\mathrm{~S})$ & & $2.62 \& 0.012(\mathrm{~S})$ \\
\hline & Multiple & 37 & $15.4 \pm 6.22$ & & $11.2 \pm 3.36$ & \\
\hline \multirow{3}{*}{ Recurrent GW } & Yes & 21 & $12.9 \pm 5.39$ & $4.99 \&$ & $11.7 \pm 2.66$ & \\
\hline & & & & $<0.001(\mathrm{~S})$ & & $2.33 \& 0.024(\mathrm{~S})$ \\
\hline & No & 29 & $20.2 \pm 4.88$ & & $9.6 \pm 3.54$ & \\
\hline \multirow{3}{*}{$\begin{array}{l}\text { Husband } \\
\text { infection } \\
\text { with GWs }\end{array}$} & Yes & 39 & $17.1 \pm 6.32$ & & $10.5 \pm 3.49$ & \\
\hline & & & & $0.11 \& 0.91(\mathrm{NS})$ & & $0.27 \& 0.78(\mathrm{NS})$ \\
\hline & No & 11 & $17.3 \pm 6.14$ & & $10.2 \pm 2.93$ & \\
\hline \multirow{3}{*}{ Condom use } & Yes & 9 & $19.6 \pm 7.23$ & & $9.1 \pm 2.31$ & \\
\hline & & & & $1.35 \& 0.18(\mathrm{NS})$ & & $1.4 \& 0.16(\mathrm{NS})$ \\
\hline & No & 41 & $16.6 \pm 5.93$ & & $10.8 \pm 3.48$ & \\
\hline \multirow{3}{*}{ TTT type } & Cryotherapy & 43 & $17.0 \pm 6.34$ & & $10.8 \pm 3.30$ & \\
\hline & $\begin{array}{l}\text { Podophyllin } \\
\text { solution }\end{array}$ & 5 & $17.6 \pm 6.77$ & $\begin{array}{c}\mathrm{ANOVA}=0.14 \\
\& 0.87(\mathrm{NS})\end{array}$ & $8.8 \pm 3.63$ & $\begin{array}{c}\text { ANOVA }=1.44 \\
\& 0.27(\mathrm{NS})\end{array}$ \\
\hline & $\begin{array}{c}\text { Candida antigen } \\
\text { injection }\end{array}$ & 2 & $19.3 \pm 3.39$ & & $8.0 \pm 2.82$ & \\
\hline
\end{tabular}

\section{DISCUSSION}

The highly-visible and recurrent nature of GWs may directly and negatively impact libido and sexual function, possibly leading to significant psychosocial burden of negative self-image and consternation for both patient and partner ${ }^{[11]}$. In this study, $98 \%$ of the participants had sexual dysfunction which is in agreement with the study of Graziottin and Serafini ${ }^{[12]}$, who reported that GWs may have a negative impact on feelings about sex.

Concerning FSFI scores, the total score was $17.2 \pm 6.2$ that meant sexual dysfunction with decline in all aspects of the female sexual function. This is in accordance with the study of Morin et al. ${ }^{[13]}$, whereas genital warts associated with decreased sexual desire, more difficult arousal and dyspareunia. Alike, Palefsky ${ }^{[14]}$ stated that GWs were associated with psychological effects and psychosexual dysfunction.

Patients with GWs were affected on most DLQI items, including sexual difficulties, feelings e.g. embarrassment, more treatment problems, some patients had severe disturbances with their husbands, which almost led to divorce. This was in agreement with Graziottin and Serafini ${ }^{[12]}$, reporting that patients with GWs had negative feelings including fear and anxiety about cancer and becoming ill, concerns about fertility, feelings of being unclean because of the sexually transmitted nature of HPV, concerns about transmission and sexual relationships, and relationship issues including blaming a partner for the infection. Feelings of blameworthy, doubts concerning transmission and assumed dishonest were behind the breakdown of the relationship between our patients and their partners that may lead to divorce.

In the current study, there was association between FSD and decreased QOL. The sexual dysfunction and quality of life often interfered with each other. Any physical or psychologic disorders that could affect one's quality of life also affect sexual function. Moreover, the inability to have normal sexual life can erode an individual's sense of self-esteem and lead to emotional and marital tension ${ }^{[15]}$.

According to our findings, a significant relation was determined between the women having sexual problems in terms of women age, duration of marriage, disease duration, HPV knowledge, GWs characters (number, recurrence). Age was a significant factor in 
experiencing sexual problems, where women older than 30 years have a higher risk of being less satisfied with their sexual life, consistent with the revealed by Odar et al. ${ }^{[16]}$. This may be due to higher level of energy and less fatigue in younger women ${ }^{[17]}$.

In the present study, $74 \%$ of women had multiple GWs with a significant negative effect on FSFI score, which was in agreement with previous studies ${ }^{[18,19]}$ whereas increasing number of warts significantly associated with lower scores on the sexual activity dimension.

In the current research, there was higher levels of HPV knowledge among patients with higher levels of education, this in accordance with Benning and Lund 20; Hanisch et al. ${ }^{[21]}$. Also, there was a significant negative correlation between QOL and the disease duration, number of GWs, recurrent GWs. Schiller et al. ${ }^{[22]}$ reported that an increase in number of genital warts resulted in a steep decline in well-being among women.

Amongst our participants, $68 \%$ felt pain, embarrassment and worried about treatment effectiveness and duration, this was in agreement with Stanley ${ }^{[23]}$, who reported that HPV genital lesions' treatment may be long, painful, and can cause sexual impairments.

Finally, effects of GWs on FSD and QOL may be explained by the taboo over the presence of GWs, which are highly visible lesions. The increased access to effective information and communication are important to lessen negative sexual consequences and anxiety about $\mathrm{GWs}^{[24]}$.

\section{Study limitations}

The major limitation of our research was its methodology with no control group of non-infected women with GWs. Moreover, the sample size was not large enough to get a high level of reliability. The study was carried out on patients referred to Dermatology and Gynecology \& Obstetrics Outpatient Clinics of Dermatology \& Andrology Department and Gynecology \& Obstetrics Department in Benha University Hospital, which may not be the true representative picture in the general population.

\section{CONCLUSION}

GWs may have negative effects on patients' quality of life; because they affect self-perception and social affiliations. Since, they affect all domains of sexual function GWs may have negative impact on sexual life.
Effective data and communication are vital to diminish undesirable sexual consequences and anxiety.

\section{CONFLICT OF INTEREST}

There are no conflicts of interest.

\section{REFERENCES}

1. Badia X, Colombo JA, Lara N, Llorens MA, Olmos L, Sainz de los Terreros M, Varela JA, Vilata JJ. Combination of qualitative and quantitative methods for developing a new health related quality of life measure for patients with anogenital warts. Health Qual Life Outcomes. 2005; 3:24.

2. Lee Mortensen G, Kiellberg Larsen H. The quality of life of patients with genital warts: a qualitative study. BMC Public Health. 2010; 10:113.

3. Aslan E, Fynes M. Female sexual dysfunction. Int Urogynecol J Pelvic Floor Dysfunct 2008; 19: 293-305.

4. Jeynes C, Chung MC, Challenor R. 'Shame on you' - the psychosocial impact of genital warts. Int J STD AIDS. 2009; 20:557-560.

5. Woodhall S, Ramsey T, Cai C, Crouch S, Jit M, Birks Y, Edmunds WJ, Newton R, Lacey CJ. Estimation of the impact of genital warts on health-related quality of life. Sex Transm Infect.2008;84(3):161-166.

6. Rosen R, Brown C, Heiman J, et al. The Female Sexual Function Index (FSFI): a multidimensional self-report instrument for the assessment of female sexual function. J Sex Marital Ther. 2000;26(2):191-208.

7. Anis TH, Gheit SA, Saied HS, Al kherbash SA. Arabic Translation of Female Sexual Function Index and Validation in an Egyptian Population. J Sex Med. 2011 Dec; 8(12):3370 -8.

8. Wiegel M, Meston C, Rosen R. The Female Sexual Function Index (FSFI): Cross-validation and Development of Clinical Cutoff Scores. J Sex Marital Ther. 2005; 31:1.

9. Basra MK, Fenech R, Gatt RM, Salek MS, Finlay AY. The dermatology life quality index19942007-: A comprehensive review of validation data and clinical results.Br J Dermatol. 2008; 159:997-1035.

10. Finlay AY, Khan GK. Dermatology life quality index (DLQI)-: A simple practical measure for routine clinical use.Clin Exp Dermatol. 1994; 19:210-6. 
11. Dominiak-Felden G, Cohet., Atrux-Tallau S, Gilet H, Tristram A, Fiander A: Impact of human papillomavirus-related genital diseases on quality of life and psychosocial wellbeing: results of an observational, health related quality of life study in the UK. BMC Public Health. 2013 Nov 12; 13:1065.

12. Graziottin A., Serafini A. HPV infection in women: psychosexual impact of genital warts and intraepithelial lesions. Journal of Sexual Medicine. 2009;6(3):633-645.

13. Morin C, Bouchard C, Brisson J, Fortier M, Blanchette C, Meisels A. Human papillomaviruses and vulvar vestibulitis. Obstet Gynecol. 2000;95:683-7.

14. Palefsky J: Human papillomavirus-related disease in men: Not just a women's issue. J AdolescHealth . 2010;46(4 suppl):S12-9 PMCID: PMC2871537

15. Althof, S.E. Quality of life and erectile dysfunction. Urology. 2002; 59:803-810.

16. Odar E, Wandabwa J, Kiondo P. Sexual practices of women within six months of childbirth in Mulago hospital, Uganda. Afr Health Sci. 2003; 3(3):117 -23.

17. Shirvani MA, Nesami MB, Bavand M: Maternal sexuality after child birth. Pak J Biol Sci . 2010, 8:385-389.

18. Drolet M, Brisson M, Maunsell E, Franco EL, Coutlee F, Ferenczy A. The impact of anogenital warts on health-related quality of life: a 6-month prospective study. Sex Transm Dis. 2011; 38(10):949-956.

19. Woodhall SC, Jit M, Soldan K, Kinghorn G, Gilson R, Nathan M. The impact of genital warts: loss of quality of life and cost of treatment in eight sexual health clinics in the UK. Sex Transm Infect. 2011; 87(6):458-463.

20. Benning BR, Lund MR. Patient knowledge about human papillomavirus and relationship to history of abnormal Papanicolaou test results. J Low Genit Tract Dis. 2007;11 (1):29.

21. Hanisch R, Gustat J, Hagensee ME, Baena A, Salazar JE, Castro MV. Knowledge of Pap screening and human papillomavirus among women attending clinics in Medellin, Colombia. Int J Gynecol Canc. 2008; 18(5):1020-1026.

22. Schiller JT, Castellsague X, Garland SM: A review of clinical trials of human papillomavirus prophylactic vaccines. Vaccine. 2012, 30 (Suppl 5): F123-F138.

23. Stanley M. A. Genital human papillomavirus infections: current and prospective therapies. Journal of General Virology. 2012; 93(4):681-691

24. Nagele E, Reich O, Greimel E, Dorfer M, Haas J, Trutnovsky G: Sexual Activity, Psychosexual Distress, and Fear of Progression in Women With Human Papillomavirus-Related Premalignant Genital Lesions. J Sex Med. 2016 Feb; 13(2):25 3- 9. 